2016 (58) 4

Tijdschrift voor

\title{
Criminologie
}

\section{Street-level bureaucracy en actoren in de veiligheidszorg}

Boomeriminologie 


\section{Tijdschrift voor Criminologie}

Tijdschrift voor Criminologie 2016, 58(4), 1-125

Formule

Het Tijdschrift voor Criminologie is sinds 1958 hét Nederlandstalige publicatiepodium voor de strikt wetenschappelijke en onafhankelijke bestudering van problemen rond criminaliteit, straf en (on)veiligheid. Het biedt wetenschappers en mensen uit de praktijk vier keer per jaar een mix van resultaten van empirisch onderzoek, kritische evaluaties van onderzoekmethoden en theoretisch denkwerk. Afwisselend verschijnen varia- en themanummers.

\section{Redactie}

Prof. dr. mr. A.A.J. Blokland, NSCR Amsterdam, Universiteit Leiden

Dr. A.M. van der Laan, WODC, Ministerie van Justitie, Den Haag

Prof, dr. S. Pleysier, K.U. Leuven

Prof. dr. C.J. de Poot, VU Amsterdam

Prof. dr. A.C.M. Spapens, Universiteit van Tilburg

Prof. dr. A. Verhage, Universiteit Gent

Dr. C.G. van Wingerde, Erasmus School of Law, Rotterdam

Boeken- en Kroniekenredacteur:

L. van Reemst, MSc, Erasmus School of Law, Rotterdam

\section{Redactiesecretariaat}

Kopij en recensie-exemplaren naar:

Redactiesecretariaat TvC

t.a.v. mr. C.Y.M. Helmer

Postbus 71304

1008 BH Amsterdam

e-mail redactie.tvc@nscr.nl

website www.criminologie.nl/tvc.

\section{Aanwijzingen voor auteurs}

Artikelen voor varianummers (twee keer per jaar) moeten zijn gebaseerd op oorspronkelijk wetenschappelijk onderzoek en niet eerder in eenzelfde of gelijkende vorm zijn gepubliceerd. Bij de (anonieme) beoordeling door de redactie wordt het oordeel van externe deskundigen betrokken.

Ingezonden manuscripten hebben een maximale lengte van 6.000 woorden, incl. noten,

literatuurlijst en Engelstalige samenvatting van 100 woorden, alles in Word. Voor gedetailleerde auteursaanwijzingen zie www.criminologie.nl/ tvc. Inleverdata volgende varianummers:

9 januari 2017, 20 maart 2017 en 8 mei 2017.

\section{Open Access-beleid}

Zes maanden na verschijning van het artikel staat het de auteur vrij om de definitieve pdf van zijn wetenschappelijke publicatie op het internet toegankelijk te maken. Voor meer informatie zie www.boomcriminologie.nl/open_access. Boom criminologie gaat ervan uit dat de auteur akkoord is met de daar te vinden licentievoorwaarden.
Uitgever

Boom criminologie

Kanonstraat 4-IV

Postbus 85576

2508 CG Den Haag

tel. $070-3307033$

e-mail infoøoomcriminologie.nl

website www.boomcriminologie.nl

\section{Abonnementen}

Het Tïdschrift voor Criminologie verschijnt vier keer per jaar. De abonnementsprijs bedraagt voor $2017 € 167,00$ per jaar (excl. btw, incl. verzendkosten) voor een plusabonnement. Studenten betalen $€ 69$ (ind. btw en verzendkosten) voor een folio-abonnement. Deze prijzen zijn inclusief het lidmaatschap van de Nederlandse Vereniging voor Kriminologie (NVK), Een plusabonnement biedt $u$ naast de gedrukte nummers tevens het online-archief vanaf 2005 en een e-mail-attendering. Kijk op www.tijdschriften boomcriminologie.nl voor meer informatie. Abonnementen kunnen op elk gewenst tijdstip ingaan. Valt de aanvang van een abonnement niet samen met het kalenderjaar, dan wordt over het resterende gedeelte van dat jaar een evenredig deel van de abonnementsprijs in rekening gebracht. Het abonnement kan alleen schriftelijk tot uiterlijk 1 december van het lopende abonnementsjaar worden opgezegd. Bij niet-tijdige opzegging wordt het abonnement automatisch voor een jaar verlengd.

Voor een abonnement kunt $\mathrm{u}$ contact opnemen met Boom distributiecentrum via 0522-23 7555 of tijdschriften@boomdistributiecentrum.nl. Het abonnement kunt $u$ tevens afsluiten via www.tijdschriften.boomcriminologie.nl.

\section{Advertenties}

Voor het plaatsen van een advertentie in dit tijdschrift kunt u contact opnemen met Capital Media Services BV, tel. 024-3607710, e-mail mail@capitalmediaservices.nl.

ISSN 0165-182x

\section{Nederaids ueversverbond \\ Groep uitgevers voor \\ vak en wetenschap}

\section{Inhoudsopga}

Redactioneel

Street-level bureaucrac Emile Kolthoff, Kim Loy

\section{Artikelen}

Interview: 'Frontlijnw In gesprek met Micha Jorrit de Jong

Street-level bureaucra Nederlandse penitent Discrepanties tussen Anouk Bosma, Maarten

De discretionaire ruin Jannie Noppe

Street-level bureaucra Hoe groepsleiders hui Marie-José Geenen, En Jeanet de Jong

Onderzoeksnotities Criminaliteit relatere Wim Bernasco \& Chan

\section{Kroniek}

Wat als er niets is? Eric Rassin

\section{Boekbesprekingen} Mum's the word. As psychosocial functio An Nuytiens

Understanding varia choice perspective Marre Lammers 
Tijdschrift voor Criminologie

2016 (58) 4

\section{Inhoudsopgave}

\section{Redactioneel}

Street-level bureaucracy en actoren in de veiligheidszorg

Emile Kolthoff, Kim Loyens \& Antoinette Verhage

\section{Artikelen}

Interview: 'Frontlijnwerk is duidelijker geworden - niet eenvoudiger'

In gesprek met Michael Lipsky

Jorrit de Jong

Street-level bureaucracy en verwijzingen naar gedragsinterventies in Nederlandse penitentiaire inrichtingen

Discrepanties tussen beleid en praktijk

Anouk Bosma, Maarten Kunst, Anja Dirkzwager \& Paul Nieuwbeerta

De discretionaire ruimte bij het gebruik van geweld: hoe kleiner, hoe beter? Jannie Noppe

Street-level bureaucrats in de justitiële jeugdinrichting?

Hoe groepsleiders hun discretionaire ruimte benutten

Marie-José Geenen, Emile Kolthoff, Robin Christiaan van Halderen \&

Jeanet de Jong

\section{Onderzoeksnotities}

Criminaliteit relateren aan verblijfspopulaties

Wim Bernasco \& Chantal van den Berg

\section{Kroniek}

Wat als er niets is?

Eric Rassin

\section{Boekbesprekingen}

Mum's the word. A study on children of incarcerated mothers' well-being, psychosocial functioning, and caregiving situation

An Nuytiens

Understanding variation in distance to crime from within the rational choice perspective

Marre Lammers 